\title{
Clinical risk factors in SUDEP
}

\section{A nationwide population-based case-control study}

Olafur Sveinsson, MD, MSc, Tomas Andersson, BSc, Peter Mattsson, MD, PhD, Sofia Carlsson, PhD, and Torbjörn Tomson, MD, PhD

Neurology ${ }^{\circledR}$ 2020;94:e419-e429. doi:10.1212/WNL.0000000000008741

\section{Abstract}

\section{Objective}

We conducted a nationwide case-control study in Sweden to test the hypothesis that specific clinical characteristics are associated with increased risk of sudden unexpected death in epilepsy (SUDEP).

\section{Methods}

The study included 255 SUDEP cases (definite and probable) and 1,148 matched controls. Clinical information was obtained from medical records and the National Patient Register. The association between SUDEP and potential risk factors was assessed by odds ratios (ORs) and 95\% confidence intervals (CIs) and interaction assessed by attributable proportion due to interaction $(\mathrm{AP})$.

\section{Results}

Experiencing generalized tonic-clonic seizures (GTCS) during the preceding year was associated with a 27-fold increased risk (OR 26.81, 95\% CI 14.86-48.38), whereas no excess risk was seen in those with exclusively non-GTCS seizures (OR 1.15, 95\% CI 0.54-48.38). The presence of nocturnal GTCS during the last year of observation was associated with a 15 -fold risk (OR 15.31, 95\% CI 9.57-24.47). Living alone was associated with a 5-fold increased risk of SUDEP (OR 5.01, 95\% CI 2.93-8.57) and interaction analysis showed that the combination of not sharing a bedroom and having GTCS conferred an OR of 67.10 (95\% CI 29.66-151.88), with AP estimated at 0.69 (CI 0.53-0.85). Among comorbid diseases, a previous diagnosis of substance abuse or alcohol dependence was associated with excess risk of SUDEP.

\section{Conclusions}

Individuals with GTCS who sleep alone have a dramatically increased SUDEP risk. Our results indicate that $69 \%$ of SUDEP cases in patients who have GTCS and live alone could be prevented if the patients were not unattended at night or were free from GTCS.

\section{Correspondence} Dr. Sveinsson olafur.sveinsson@sll.se

\section{RELATED ARTICLE}

\section{Patient Page}

Sudden unexpected death in epilepsy: Assessing the risk factors

Page e436

\section{MORE ONLINE}

\section{- CME Course}

NPub.org/cmelist 


\section{Glossary}

AED = antiepileptic drug; AP = proportion attributable to interaction; $\mathbf{C I}=$ confidence interval; $\mathbf{G T C S}=$ generalized tonicclonic seizures; ICD = International Classification of Diseases; LISA = longitudinal integration database for health insurance and labor market studies; OR = odds ratio; SNPR = Swedish National Patient Register; SUDEP = sudden unexpected death in epilepsy; VNS = vagus nerve stimulation.

Sudden unexpected death in epilepsy (SUDEP) is the most important epilepsy-related cause of death, ranking second only to stroke among neurologic diseases in terms of potential years of life lost. ${ }^{1}$ Several case-control studies have attempted to identify risk factors for SUDEP ${ }^{2-5}$ to provide a basis for an individualized risk assessment. By pooling data from 4 such studies, frequency of generalized tonic-clonic seizures (GTCS) in particular, but also the duration of epilepsy, young age at epilepsy onset, and male sex, were identified as risk factors. ${ }^{6}$ However, a recent systematic review concluded that the frequency of GTCS was the only risk factor identified with a high level of confidence, whereas, e.g., lack of nighttime supervision and absence of nocturnal listening device were risk factors with moderate confidence. $^{7}$ Other risk factors, including young age at epilepsy onset, long duration of epilepsy, focal epilepsy, and intellectual disability, have been proposed in individual studies, ${ }^{8}$ but the evidence was considered low in the systematic review. ${ }^{7}$ The uncertainty can be attributed to methodologic limitations such as small numbers and selected study populations affecting generalizability. ${ }^{2-5}$ Differences in definitions of potential risk factors have also hampered pooling of data. ${ }^{6,7}$ To guide patient counseling and for the development of effective SUDEP preventions, there is still need for large, high-quality studies to elucidate SUDEP risk factors. ${ }^{7}$ Therefore, we analyzed the risk of SUDEP in relation to a range of potential risk factors in a large, nationwide population-based case-control study in Sweden utilizing data from individual medical records and national registries.

\section{Methods}

\section{SUDEP definition and classification}

SUDEP is defined as sudden, unexpected, witnessed or unwitnessed, nontraumatic, and nondrowning death of patients with epilepsy with or without evidence of a seizure, excluding documented status epilepticus, and in whom postmortem examination does not reveal a structural or toxicologic cause for death. ${ }^{9}$ In the present study, we classified SUDEP cases according to Anneger ${ }^{10}$ criteria. This classification was selected to facilitate comparison since it has been used in most previous studies. ${ }^{2-5}$ SUDEP cases were divided into 3 subgroups based on the certainty of the diagnosis: (1) definite SUDEP when all clinical criteria are met and an autopsy is performed that reveals no alternative cause of death; (2) probable SUDEP when all clinical criteria are met but no autopsy is performed; and (3) possible
SUDEP when SUDEP cannot be ruled out, but there is insufficient evidence regarding the circumstances of the death and no autopsy is performed. ${ }^{10}$

\section{Study population}

The Swedish National Patient Register (SNPR) contains all patients hospitalized (starting in 1968, with total national coverage from 1987) or managed in hospital-based ambulatory care (since 2001) in Sweden. ${ }^{11}$ Each individual's outpatient visit or hospital discharge diagnosis (ICD code) is linked with a unique personal identification number. We identified all persons who at some point during 1998-2005 were registered in the SNPR with an ICD-10 code for epilepsy (G40) $(\mathrm{n}=78,424)$ and alive on June 30, $2006(\mathrm{n}=60,952)$. This constituted our study population.

\section{Cases}

During follow-up from July 1, 2006, to December 31, 2011, 9,605 deaths were identified by linkage to the National Cause of Death Registry (ICD-10 classified since 1994). ${ }^{12}$ Eligible SUDEP cases were all deaths with epilepsy mentioned on the death certificate $(n=1,276)$, together will all individuals who died during $2008(\mathrm{n}=1,890)$ (figure 1). We previously conducted a study of the incidence of SUDEP during $2008,{ }^{13}$ which is why all deaths in the study population were reviewed that particular year. All death certificates were reviewed by one neurologist (O.S.). Obvious non-SUDEP deaths such as cancer, terminal illness, postmortem confirmed pneumonia, stroke, or myocardial infarction were excluded from further analysis based on the information in the death certificates (figure 1). This process considered all information on the death certificate, postmortem results, and whether the patient died in the hospital. For the remaining cases, where SUDEP could potentially be the cause of death $(n=1,373)$, patient records from family physicians, hospital records, nursing homes or other institutions, police records, and autopsy records were reviewed (O.S.) and all information was extracted using a standardized protocol. Emphasis was on attaining the doctor's or police report regarding circumstances surrounding the death, including documented interviews with eyewitnesses, caregivers, and relatives. All information was reviewed by 2 neurologists (O.S. and T.T.) and classification of the cases was made through consensus. From patient records, we determined if the patients met the criteria for a diagnosis of epilepsy according to the definition of the International League Against Epilepsy. ${ }^{14}$ In the end, 255 definite $(n=167)$ and probable $(\mathrm{n}=88)$ cases according to the Anneger classification were found and served as cases for this study 


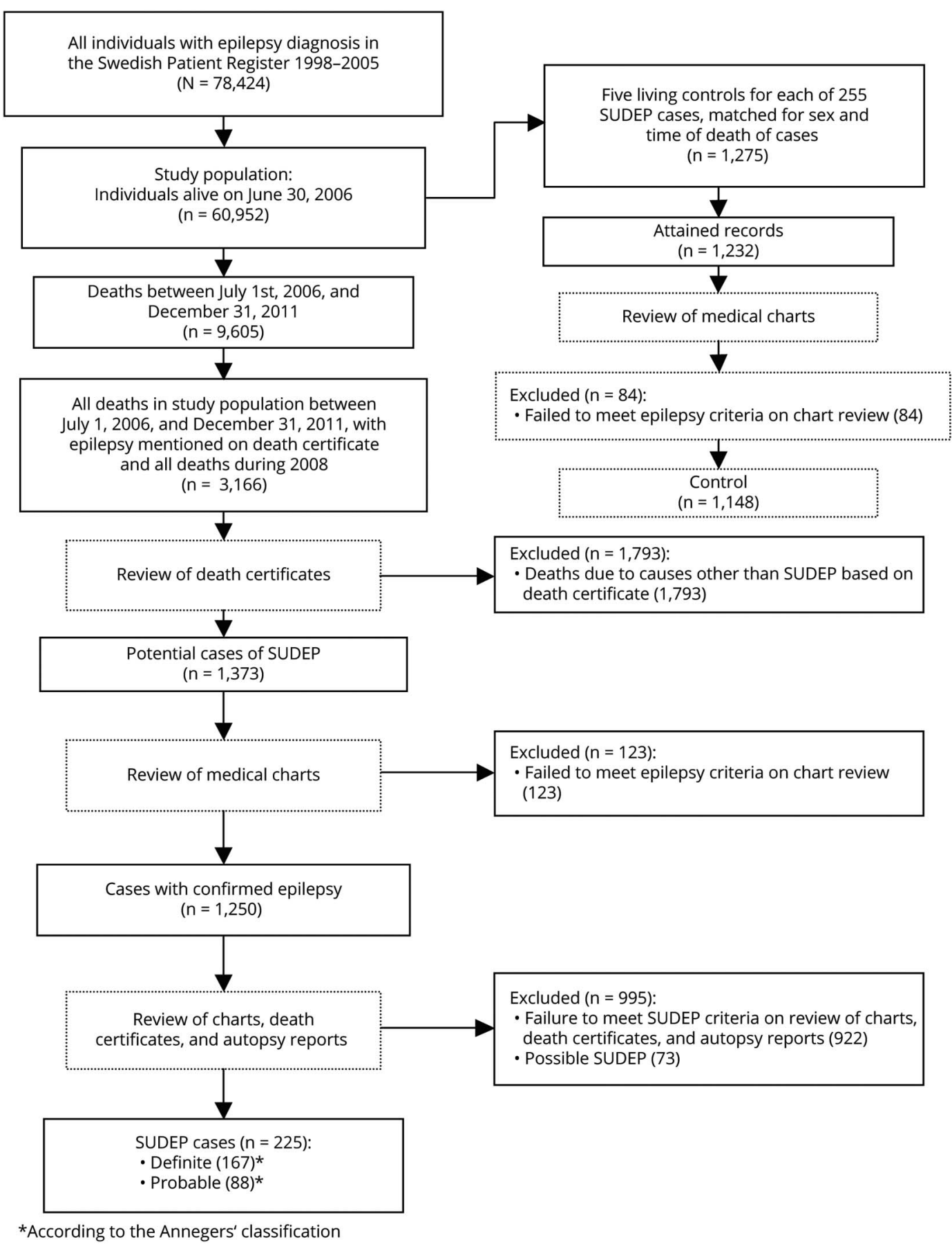

SUDEP = sudden unexpected death in epilepsy.

(figure 1). Possible SUDEP cases $(\mathrm{n}=73)$ were not used in this study.

\section{Controls}

From the study population, the National Board of Health and Welfare randomly selected 5 epilepsy controls $(n=1,275)$ for each person with SUDEP, of the same sex, who were alive at the case's time of death, which served as an index date for the controls. For these controls, we requested patient records from caregivers across the country and attained records for 1,232 (97\%) individuals. Of these, 84 (6.8\%) were judged not to have epilepsy. This left 1,148 individuals, who served as controls in the present study (figure 1).

\section{Information from patient records}

For all cases and controls, we used patient records to collect information on age, sex, and living condition (living alone or with others, including parents, partners, children, and siblings, 
Table 1 Demographic and clinical characteristics of cases and controls

\begin{tabular}{|c|c|c|c|c|c|c|}
\hline & \multicolumn{2}{|l|}{ All } & \multicolumn{2}{|l|}{ Men } & \multicolumn{2}{|l|}{ Women } \\
\hline & Cases & Controls & Cases & Controls & Cases & Controls \\
\hline No. (\%) & 255 & 1,148 & $154(60.4)$ & $680(59.2)$ & $101(39.6)$ & $468(40.8)$ \\
\hline $\begin{array}{l}\text { Age at death, y/index, mean } \\
\text { (range) }\end{array}$ & $47(4-92)$ & $39(3-94)$ & $48(4-92)$ & $39(3-93)$ & $45(5-88)$ & $40(3-94)$ \\
\hline $\begin{array}{l}\text { Age at epilepsy diagnosis, } y \text {, mean } \\
\text { (range) }\end{array}$ & $22.4(0-86)$ & $20.0(0-86)$ & $23.7(0-86)$ & $20.0(0-84)$ & $20.6(0-84)$ & $20.0(0-86)$ \\
\hline $\begin{array}{l}\text { Duration of epilepsy, } y, \text { mean under } \\
\text { (range) }\end{array}$ & $24(1-81)$ & $20(1-78)$ & $24(2-70)$ & $19(1-76)$ & $24(1-81)$ & $21(2-78)$ \\
\hline \multicolumn{7}{|l|}{ Type of epilepsy, n (\%) } \\
\hline Generalized & $37(14.5)$ & $267(23.3)$ & $15(9.7)$ & $146(21.3)$ & $22(21.8)$ & $121(26.1)$ \\
\hline Focal & $186(73.0)$ & $794(69.3)$ & $117(76.0)$ & $478(70.0)$ & $68(67.3)$ & $316(68.1)$ \\
\hline Focal and generalized & $10(4.0)$ & $31(2.7)$ & $6(3.9)$ & $20(3.0)$ & $4(4.0)$ & $11(2.4)$ \\
\hline Unknown & $22(8.6)$ & $56(4.9)$ & $15(9.7)$ & $40(5.8)$ & $7(6.9)$ & $16(3.4)$ \\
\hline \multicolumn{7}{|l|}{ Causes of epilepsy, n (\%) } \\
\hline Genetic & $48(18.8)$ & $303(26.4)$ & $21(13.6)$ & $164(24.0)$ & $26(25.6)$ & $139(30.0)$ \\
\hline Structural & $129(50.6)$ & $444(38.7)$ & $85(55.2)$ & $279(40.8)$ & $26(25.6)$ & $165(35.6)$ \\
\hline Infectious & $12(4.7)$ & $42(3.7)$ & $8(5.2)$ & $28(4.1)$ & $4(4.0)$ & $14(3.0)$ \\
\hline Metabolic & $2(0.8)$ & $9(0.8)$ & $1(0.6)$ & $7(1.0)$ & $1(1.0)$ & $2(0.4)$ \\
\hline Autoimmune & $2(0.8)$ & $10(0.9)$ & $1(0.6)$ & $4(0.6)$ & $1(1.0)$ & $6(12.9)$ \\
\hline Unknown & $66(25.9)$ & $359(31.3)$ & $39(25.3)$ & $214(31.3)$ & $27(26.7)$ & $145(31.2)$ \\
\hline \multicolumn{7}{|l|}{ Living conditions, n (\%) } \\
\hline Sharing household and bedroom & $32(12.5)$ & $391(34.1)$ & $19(12.3)$ & $210(30.9)$ & $13(12.9)$ & $181(38.7)$ \\
\hline Sharing household but not bedroom & $49(19.2)$ & $398(34.7)$ & $27(17.5)$ & $252(37.1)$ & $22(21.8)$ & $146(31.2)$ \\
\hline Not sharing household & $174(68.2)$ & $304(26.5)$ & $108(70.1)$ & $177(26.0)$ & $66(65.3)$ & $127(27.1)$ \\
\hline Unknown & 0 & $55(4.8)$ & 0 & $41(6.0)$ & 0 & $14(3.0)$ \\
\hline \multicolumn{7}{|l|}{ Highest education, n (\%) } \\
\hline Postsecondary education & $26(10.2)$ & $168(14.6)$ & $17(11.0)$ & $96(14.1)$ & $9(8.9)$ & $72(15.4)$ \\
\hline $\begin{array}{l}\text { High school/secondary } \\
\text { education }\end{array}$ & $86(33.7)$ & $359(31.3)$ & $53(34.4)$ & 201 (29.6) & $33(32.7)$ & $158(33.8)$ \\
\hline Primary education & $86(33.7)$ & $297(25.8)$ & $56(36.4)$ & $171(25.1)$ & $30(29.7)$ & $126(26.9)$ \\
\hline Missing education $^{a}$ & $57(22.4)$ & $324(28.2)$ & $28(18.2)$ & $212(31.2)$ & $29(28.7)$ & $112(23.9)$ \\
\hline
\end{tabular}

a Younger than 16 and those who did not attend regular school.

and if sharing a bedroom). If cases or controls were married or had a partner, they were classified as sharing a bedroom, if not otherwise explicitly stated. Further information was collected on epilepsy onset, duration of epilepsy, type of epilepsy, etiology, ${ }^{15}$ history of tonic-clonic seizures (in this context including both generalized tonic-clonic seizures and focal to bilateral tonic-clonic seizures in accordance with most previous case-control studies of SUDEP), ${ }^{14}$ presence and frequency of tonic-clonic nocturnal seizures during the last year of observation, presence of other seizures during the last year of observation, history of nocturnal seizures, history of tonicclonic nocturnal seizures, presence of tonic-clonic nocturnal seizures during the last year of observation, intellectual disability, antiepileptic drug (AED) treatment, and whether the patient had undergone epilepsy surgery or had ongoing treatment with vagus nerve stimulation (VNS).

\section{Information from national registries}

Information on psychiatric comorbidity, pulmonary disease, and cardiovascular disease was obtained from ICD codes in 
Table 2 Sudden unexpected death in epilepsy in relation to clinical characteristics, living conditions, and education

\begin{tabular}{|c|c|c|c|c|c|}
\hline & Cases & Controls & Model $1^{a}$ & Model $2^{b}$ & Model $3^{c}$ \\
\hline \multicolumn{6}{|l|}{ Age at onset, y } \\
\hline$<18$ & 140 & 724 & $1.15(0.81-1.63)$ & $0.63(0.39-1.01)$ & $0.60(0.34-1.05)$ \\
\hline $18-65$ (ref) & 96 & 344 & 1 & 1 & 1 \\
\hline Over 65 & 14 & 62 & $0.61(0.27-1.38)$ & $0.55(0.20-1.56)$ & $0.65(0.21-2.05)$ \\
\hline \multicolumn{6}{|l|}{ Duration of epilepsy, y } \\
\hline$\leq 15$ (ref) & 102 & 586 & 1 & 1 & 1 \\
\hline$>15$ & 153 & 548 & $1.22(0.89-1.67)$ & $0.71(0.46-1.08)$ & $0.81(0.50-1.31)$ \\
\hline \multicolumn{6}{|l|}{ Type of epilepsy } \\
\hline Generalized (ref) & 37 & 267 & 1 & 1 & 1 \\
\hline Focal & 186 & 794 & $1.48(1.00-2.20)$ & $1.62(0.98-2.66)$ & $1.34(0.77-2.33)$ \\
\hline Focal and generalized & 10 & 31 & $3.51(1.55-7.96)$ & $2.05(0.77-5.50)$ & $1.42(0.49-4.15)$ \\
\hline Unknown & 22 & 56 & $2.43(1.29-4.57)$ & $3.06(1.36-6.90)$ & $3.51(1.44-8.55)$ \\
\hline \multicolumn{6}{|l|}{ Cause of epilepsy ${ }^{d}$} \\
\hline Genetic & 48 & 303 & $0.84(0.35-2.00)$ & $0.84(0.33-2.19)$ & $0.83(0.29-2.41)$ \\
\hline Structural & 129 & 444 & $1.36(0.56-3.27)$ & $1.38(0.52-3.64)$ & $1.20(0.41-3.52)$ \\
\hline Infectious & 12 & 42 & $1.37(0.46-4.02)$ & $0.89(0.27-2.91)$ & $1.11(0.30-4.13)$ \\
\hline Metabolic & 2 & 9 & $1.39(0.28-6.91)$ & $1.24(0.17-8.91)$ & $2.09(0.31-14.06)$ \\
\hline Autoimmune & 2 & 10 & $1.00(0.18-5.76)$ & $2.89(0.39-21.68)$ & $2.41(0.21-27.51)$ \\
\hline Unknown & 66 & 359 & $0.89(0.36-2.22)$ & $1.17(0.43-3.21)$ & $1.07(0.35-3.25)$ \\
\hline \multicolumn{6}{|l|}{ Living conditions } \\
\hline Sharing household and bedroom (ref) & 32 & 391 & 1 & 1 & 1 \\
\hline Sharing household but not bedroom & 49 & 398 & $2.43(1.36-4.32)$ & $1.67(0.87 .22)$ & $2.28(1.14-4.58)$ \\
\hline Not sharing household & 174 & $359^{e}$ & $6.11(4.04-9.22)$ & $4.09(2.49-6.73)$ & $5.01(2.93-8.57)$ \\
\hline \multicolumn{6}{|l|}{ Highest education } \\
\hline Postsecondary education (ref) & 26 & 168 & 1 & 1 & 1 \\
\hline High school education/secondary education & 86 & 359 & $1.67(1.03-2.72)$ & $1.29(0.68-2.42)$ & $1.59(0.78-3.27)$ \\
\hline Primary education & 86 & 297 & $2.06(1.25-3.39)$ & $1.12(0.59-2.15)$ & $1.21(0.58-2.56)$ \\
\hline
\end{tabular}

Values are no. or odds ratio ( $95 \%$ confidence interval).

${ }^{a}$ Adjusted for age and sex (matching variable).

${ }^{\mathrm{b}}$ Adjusted for age, sex, and generalized tonic-clonic seizures frequency.

'Adjusted for age, sex, generalized tonic-clonic seizures frequency and nocturnal generalized tonic-clonic seizures last year of observation, living conditions (except in the analysis of living conditions), and antiepileptic drugs.

${ }^{d}$ Categories are not mutually exclusive.

e Includes 55 individuals with unknown living conditions.

the national patient registry (from 1997 to death or index date). From the longitudinal integration database for health insurance and labor market studies (LISA), which holds annual registers since 1990 and includes all individuals $16-74$ years of age, information on highest educational level was attained. ${ }^{16}$ In the LISA registry, this information is recorded as missing for individuals below 16 years and for those who did not attend regular school due to intellectual disability.

\section{Statistics}

Characteristics were expressed as mean (range) or proportion. The association between SUDEP and potential risk factors was estimated by odds ratios (ORs) with $95 \%$ confidence intervals (CIs) calculated by conditional logistic regression to account for matching by sex and calendar time. As the control participants were sampled with an incidence density method, the ORs can be interpreted as incidence rate ratios. ${ }^{17}$ In model 1 , 
Table 3 Sudden unexpected death in epilepsy in relation to type and frequency of seizures and treatment

\begin{tabular}{|c|c|c|c|c|c|}
\hline & Cases & Controls & Model $1^{a}$ & Model $2^{b}$ & Model $3^{c}$ \\
\hline \multicolumn{6}{|l|}{ History of GTCS } \\
\hline No (ref) & 4 & 174 & 1 & & 1 \\
\hline Yes & 251 & 943 & $10.56(3.86-28.86)$ & & $9.60(3.44-26.82)$ \\
\hline \multicolumn{6}{|c|}{ Seizures during preceding year } \\
\hline No (ref) & 26 & 577 & 1 & & 1 \\
\hline Yes, but not GTCS & 12 & 290 & $0.97(0.48-1.96)$ & & $1.15(0.54-2.46)$ \\
\hline GTCS & 217 & 280 & $22.70(13.72-37.55)$ & & $26.81(14.86-48.38)$ \\
\hline \multicolumn{6}{|c|}{ GTCS frequency during preceding year } \\
\hline 0 (ref) & 38 & 865 & 1 & & 1 \\
\hline $1-3$ & 106 & 150 & $19.51(11.94-31.88)$ & & $22.14(12.74-38.46)$ \\
\hline $4-10$ & 50 & 42 & $28.24(15.36-51.92)$ & & $31.87(15.95-63.67)$ \\
\hline$>10$ & 61 & 88 & $26.38(14.62-47.61)$ & & $29.70(15.04-58.63)$ \\
\hline \multicolumn{6}{|c|}{ History of nocturnal seizures } \\
\hline No (ref) & 63 & 711 & 1 & & 1 \\
\hline Yes, non-GTCS & 2 & 102 & $0.23(0.06-0.98)$ & & $0.27(0.06-1.15)$ \\
\hline Yes, GTCS & 190 & 335 & $8.44(5.91-12.04)$ & & $9.04(6.08-13.45)$ \\
\hline \multicolumn{6}{|c|}{ Nocturnal GTCS during preceding year } \\
\hline No (ref) & 145 & 1,049 & 1 & & 1 \\
\hline Yes & 110 & 99 & $12.98(8.61-19.56)$ & & $15.31(9.57-24.47)$ \\
\hline \multicolumn{6}{|l|}{ AED treatment } \\
\hline No (ref) & 19 & 144 & 1 & 1 & 1 \\
\hline Monotherapy & 120 & 546 & $1.27(0.74-2.17)$ & $0.39(0.20-0.77)$ & $0.47(0.23-0.94)$ \\
\hline Polytherapy & 115 & 458 & $1.67(0.98-2.84)$ & $0.28(0.14-0.57)$ & $0.31(0.15-0.66)$ \\
\hline \multicolumn{6}{|l|}{ Epilepsy surgery } \\
\hline No (ref) & 242 & 1,098 & 1 & 1 & 1 \\
\hline Yes & 13 & 50 & $1.27(0.66-2.44)$ & $0.89(0.39-2.00)$ & $0.77(0.31-1.92)$ \\
\hline \multicolumn{6}{|l|}{ VNS } \\
\hline No (ref) & 244 & 1,098 & 1 & 1 & 1 \\
\hline Yes & 11 & 50 & $1.29(0.65-2.57)$ & $0.50(0.22-1.11)$ & $0.41(0.17-0.98)$ \\
\hline
\end{tabular}

Abbreviations: AED = antiepileptic drug; GTCS = generalized tonic-clonic seizures; VNS = vagus nerve stimulation.

Values are no. or odds ratio ( $95 \%$ confidence interval).

${ }^{a}$ Adjusted for age and sex (matching variable).

${ }^{\mathrm{b}}$ Adjusted for age, sex, and GTCS frequency.

cAdjusted for age, sex, GTCS frequency and nocturnal GTCS last year of observation (except in the analyses of seizures), living conditions, and AEDs (except in the analysis of AED treatment).

OR was adjusted for age and sex (matching variable). Model 2 included additional adjustments for GTCS frequency and model 3 included the same covariates as model 2 together with nocturnal GTCS last year of observation, living conditions, and AEDs. In the Results, all results are presented from model 3 unless stated otherwise. Interaction between GTCS during last year of observation (yes/no) and sharing a bedroom (yes/no), defined as departure from additivity of effects, was assessed with the proportion attributable to interaction $(\mathrm{AP}) .^{18}$ The formula for $\mathrm{AP}$ is $\left(\mathrm{OR}_{11}-\mathrm{OR}_{10}-\mathrm{OR}_{01}+1\right) / \mathrm{OR}_{11}$, where $\mathrm{OR}_{11}$ indicates doubly exposed (having GTCS and sleeping alone) and $\mathrm{OR}_{01}$ or $\mathrm{OR}_{10}$ indicate either exposure (sleeping alone or having GTCS). The reference group is those with neither exposure and the ORs were adjusted for age and sex 
Table 4 Sudden unexpected death in epilepsy in relation to comorbidity (yes/no)

\begin{tabular}{|c|c|c|c|c|c|}
\hline & All, no. cases & No. controls & Model $1^{a}$ & Model $2^{b}$ & Model $3^{c}$ \\
\hline Mental health disorder & 128 & 470 & $1.69(1.28-2.25)$ & $0.85(0.59-1.23)$ & $0.80(0.54-1.19)$ \\
\hline Substance abuse & 34 & 53 & $2.57(1.63-4.05)$ & $2.01(1.10-3.66)$ & $2.07(1.07-4.01)$ \\
\hline Alcohol dependence & 26 & 34 & $2.99(1.74-5.12)$ & $2.42(1.17-5.01)$ & $2.30(1.02-5.21)$ \\
\hline Depression & 20 & 74 & $1.02(0.61-1.72)$ & $1.23(0.64-2.36)$ & $0.99(0.49-2.01)$ \\
\hline Mood (affective disorders) & 23 & 82 & $1.07(0.66-1.75)$ & $1.30(0.69-2.45)$ & $1.09(0.55-2.17)$ \\
\hline Anxiety disorder & 28 & 81 & $1.44(0.91-2.29)$ & $1.42(0.79-2.52)$ & $1.42(0.76-2.67)$ \\
\hline Intellectual disability ${ }^{d}$ & 97 & 323 & $2.48(1.79-3.42)$ & $1.07(0.69-1.66)$ & $0.90(0.54-1.51)$ \\
\hline Diseases of the nervous system, excluding epilepsy & 91 & 379 & $1.15(0.86-1.53)$ & $0.73(0.50-1.06)$ & $0.75(0.50-1.11)$ \\
\hline Diseases of the circulatory system & 88 & 327 & $0.94(0.66-1.34)$ & $0.72(0.46-1.12)$ & $0.76(0.46-1.27)$ \\
\hline Cerebrovascular disease & 45 & 145 & $1.13(0.75-1.70)$ & $1.09(0.64-1.85)$ & $1.06(0.59-1.91)$ \\
\hline Ischemic heart disease & 16 & 78 & $0.65(0.35-1.20)$ & $0.59(0.27-1.27)$ & $0.71(0.30-1.70)$ \\
\hline Heart failure & 10 & 29 & $1.35(0.61-2.99)$ & $1.05(0.36-3.10)$ & $1.23(0.39-3.92)$ \\
\hline Myocarditis, cardiomyopathy, arrhythmias & 25 & 78 & $1.19(0.71-2.00)$ & $1.08(0.55-2.11)$ & $1.25(0.61-2.54)$ \\
\hline Chronic lower respiratory diseases & 30 & 106 & $1.51(0.97-2.36)$ & $0.95(0.54-1.68)$ & $1.04(0.55-1.98)$ \\
\hline
\end{tabular}

Values are no. or odds ratio ( $95 \%$ confidence interval).

${ }^{a}$ Adjusted for age and sex (matching variable).

${ }^{\mathrm{b}}$ Adjusted for age, sex, and generalized tonic-clonic seizures frequency.

'Adjusted for age, sex, generalized tonic-clonic seizures frequency and nocturnal generalized tonic-clonic seizures last year of observation, living conditions, and antiepileptic drugs.

${ }^{d}$ Information extracted from patient records.

(matching variable). Statistical Analysis Software (SAS) 9.4 (SAS Institute, Cary, NC) was used for all analyses.

\section{Standard protocol approvals, registrations, and patient consents}

The study was approved by the Ethics Committee of Karolinska Institutet, which granted that individual informed consent was not needed.

\section{Data availability}

Anonymized data will be shared by request from qualified investigators.

\section{Results}

Characteristics of cases and controls are summarized in table 1. Among the 255 SUDEP decedents, $60.4 \%$ were men and due to matching, a similar male predominance was seen among controls. Mean age at diagnosis was 22.4 years for the SUDEP decedents and 20 years for controls and the decedents tended to have a slightly longer duration of epilepsy (24 vs 20 years). The majority of decedents had focal epilepsy $(73.0 \%)$ and of structural origin (50.6\%). Comparing cases and controls indicated small differences in the type and causes of epilepsy, but low education was slightly more common among cases (table 1). Decedents with SUDEP lived alone to a larger extent than controls, $68.2 \%$ vs $26.5 \%$, and even if they shared their household, they were less likely than controls to share a bedroom. Generalized and genetic epilepsy was less common among men with SUDEP compared to women with SUDEP and male and female controls. In a similar fashion, men with SUDEP had a slightly higher age at epilepsy onset and more often had focal and structural epilepsy.

\section{Clinical characteristics, living conditions, education, and risk of SUDEP}

Previously proposed risk factors such as young age at epilepsy onset, longer duration of epilepsy, and structural etiology were not associated with SUDEP after adjustment for GTCS frequency (table 2). As for the type of epilepsy, no excess risk was seen in individuals with focal or focal and generalized epilepsy compared to generalized epilepsy after adjustment for GTCS frequency, but epilepsy of unknown type remained associated with SUDEP. Compared with sharing a bedroom, sharing household but not bedroom was associated with a twofold increased risk and living alone was associated with a fivefold increased risk of SUDEP (OR 5.01, 95\% CI 2.93-8.57), even after adjustment for GTCS frequency and other covariates (table 2). No association between level of education and SUDEP was seen after adjustment for GTCS frequency.

\section{Seizures, treatment, and risk of SUDEP}

A history of GTCS was associated with a tenfold increased risk of SUDEP (OR 9.60, 95\% CI 3.44-26.82) (table 3). Only 4 (1.6\%) SUDEP cases did not have a history of GTCS 
Table 5 Sudden unexpected death in epilepsy in relation to the combination of generalized tonic-clonic seizures (GTCS) and living conditions

\begin{tabular}{|c|c|c|c|c|c|c|}
\hline \multirow[b]{3}{*}{ Living conditions } & \multicolumn{6}{|c|}{ GTCS frequency during preceding year } \\
\hline & \multicolumn{2}{|l|}{ No GTCS } & \multicolumn{2}{|l|}{$1-3$ GTCS } & \multicolumn{2}{|l|}{$\geq 4$ GTCS } \\
\hline & $\begin{array}{l}\text { No. cases/ } \\
\text { controls }\end{array}$ & OR $(95 \% \mathrm{Cl})$ & $\begin{array}{l}\text { No. cases/ } \\
\text { controls }\end{array}$ & OR $(95 \% \mathrm{Cl})$ & $\begin{array}{l}\text { No. cases/ } \\
\text { controls }\end{array}$ & OR $(95 \% \mathrm{Cl})$ \\
\hline $\begin{array}{l}\text { Sharing household and } \\
\text { bedroom }\end{array}$ & $8 / 318$ & 1 (ref) & $16 / 50$ & $\begin{array}{l}15.89 \\
(6.05-41.78)\end{array}$ & $8 / 21$ & $\begin{array}{l}19.85 \\
(6.37-61.84)\end{array}$ \\
\hline $\begin{array}{l}\text { Sharing household but not } \\
\text { bedroom }\end{array}$ & $4 / 287$ & $\begin{array}{l}1.10 \\
(0.30-4.02)\end{array}$ & $18 / 50$ & $\begin{array}{l}31.34 \\
(11.22-87.53)\end{array}$ & $27 / 61$ & $\begin{array}{l}33.55 \\
(12.21-92.18)\end{array}$ \\
\hline Not sharing household & $26 / 260$ & $\begin{array}{l}3.92 \\
(1.69-9.13)\end{array}$ & $72 / 50$ & $\begin{array}{l}65.90 \\
(27.72-156.65)\end{array}$ & $76 / 48$ & $\begin{array}{l}81.81 \\
(33.60-199.15)\end{array}$ \\
\hline
\end{tabular}

Abbreviations: $\mathrm{Cl}=$ confidence interval; $\mathrm{OR}=$ odds ratio.

Adjusted for age and sex (matching variable).

compared to $15.1 \%$ among the controls. In those experiencing GTCS during the last year of observation, the risk was increased 27-fold (OR 26.81, 95\% CI 14.86-48.38). Having 1-3 GTCS in the previous year was associated with a 22 -fold risk (OR 22.14, 95\% CI 12.74-38.46) and having 4-10 GTCS increased the risk to 32-fold (OR 31.87, 95\% CI 15.95-63.67), while we did not see a further risk increase when the GTCS exceeded 10 during the preceding year.

History of nocturnal GTCS was associated with a ninefold risk (OR 9.04, 95\% CI 6.08-13.45) of SUDEP and the presence of nocturnal GTCS during last year of observation, with a 15fold risk (OR 15.31, 95\% CI 9.57-24.47). In individuals experiencing exclusively non-GTCS during the preceding year, no excess risk of SUDEP was seen (OR 1.15, 95\% CI 0.54-2.46). Both monotherapy and polytherapy were associated with a reduced risk of SUDEP after adjusting for GTCS frequency and other covariates (table 3). Previous epilepsy surgery was not associated with SUDEP while vagus nerve stimulation was associated with a 59\% reduced SUDEP risk after adjustment for covariates.

\section{Comorbidity and risk of SUDEP}

Among comorbid diseases, a twofold increased risk of SUDEP was seen in individuals with a previous diagnosis of substance abuse or alcohol dependence (table 4). Mental health disorders and intellectual disability was not associated with increased SUDEP risk once we adjusted for frequency of GTCS.

\section{Interaction between living conditions and GTCS}

Table 5 displays the risk of SUDEP in relation to the combination of living conditions and GTC seizure frequency. Individuals who experienced $\geq 4$ GTCS had 20 times increased SUDEP risk if they shared a bedroom with someone, 34 times increased risk if they shared household but not bedroom, and an 82 times increased risk if they lived alone (table 5). Interaction analysis indicated that the combination of having at least one GTCS and not sharing a bedroom with someone conferred a 67-fold increased risk of SUDEP compared to not having GTCS and sharing a bedroom. AP was estimated at $0.69(0.53-0.85)$ (figure 2 ).

\section{Discussion}

Our results confirm the conclusion from previous casecontrol studies, ${ }^{2-6}$ and the recent systematic review, ${ }^{7}$ that the presence and frequency of GTCS is by far the most important risk factor for SUDEP. Importantly, we could demonstrate that having seizures other than GTCS, even at night, did not increase the risk for SUDEP. Living alone, especially not sharing a bedroom with anyone, was associated with a substantially increased risk of SUDEP and moreover, the combination of frequent GTCS and sleeping alone dramatically increased the risk of SUDEP. Taking AEDs as monotherapy or polytherapy and treatment with VNS was associated with significantly reduced risk of SUDEP whereas substance abuse and alcohol dependence appeared to increase the risk. A number of previously proposed risks were not associated with SUDEP, once we adjusted for GTCS frequency.

We saw an incremental risk increase from no seizures up to 4-10 GTCS (table 3), largely in line with the previous pooled analysis of case-control studies ${ }^{6}$ and the systematic review, ${ }^{7}$ although with somewhat higher risk estimates in our analysis. One explanation why having more than 10 GTCS per year did not increase the risk further could be that the recording of seizure counts in the medical records may be less precise in patients with a high frequency of seizures.

Interestingly, we did not observe an increased risk of SUDEP in patients with only non-GTCS. To our knowledge, this has not been specifically analyzed before. ${ }^{2-7}$ It was possible to extract this information from the extensive records we had on both cases and controls. This novel finding is important information when counseling the individual patient and in setting treatment goals. For example, improved treatment where GTCS are converted into non-GTCS could reduce the 
Figure 2 Odds ratio (OR) (95\% confidence interval [CI]) of sudden unexpected death in epilepsy by combinations of generalized tonic-clonic seizures (GTCS) and living conditions

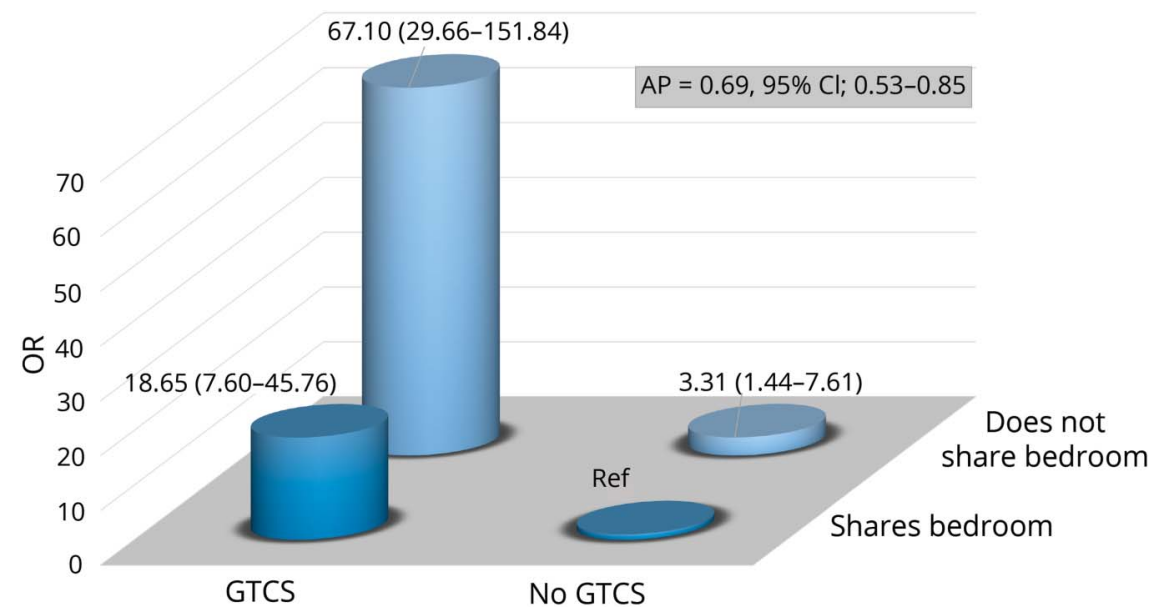

$\mathrm{AP}=$ attributable proportion due to interaction.

SUDEP risk for the individual patient. Even though there are a few reports of witnessed SUDEP without a preceding seizure or following a non-GTCS, this seems to be rare. ${ }^{19,20}$ In the MORTEMUS study of SUDEP during video-EEG monitoring, all cases followed in the aftermath of a GTCS. ${ }^{21}$

Nocturnal GTCS were associated with an increased risk of SUDEP. This fits with previous observations ${ }^{22}$ including a recent study on institutionalized individuals with epilepsy compared to controls living in the same institution. ${ }^{23}$ One novelty in our study was to analyze separately nocturnal nonGTCS demonstrating that such seizures were not associated with SUDEP.

As in previous studies, ${ }^{3-6}$ there was a trend towards increased risk in focal epilepsy which, however, disappeared after adjusting for other risk factors, especially frequency of GTCS. The group focal and generalized epilepsy was a risk factor before adjusting for GTCS, likely reflecting the severity of the epilepsy in this group. Interestingly, the unknown type of epilepsy remained a risk factor in all models. We have no clear explanation for this except that there could be similarities with this group and the focal and generalized group, where it is often difficult to classify the epilepsy due to its complex nature. It is also possible that failure to classify the type of epilepsy may be a reflection of suboptimal epilepsy management which in itself can contribute to an increased SUDEP risk.

We observed a substantial increase in SUDEP risk for those living alone, especially those not sharing a bedroom. Our observations are in line with a previous report of a protective effect of nighttime supervision, regular checks throughout the night, or use of listening devices to detect seizures. ${ }^{5}$ Furthermore, a recent study from 2 epilepsy residential care homes reported that SUDEP was more common in the center with less supervision at night. ${ }^{23}$ The greatest novelty in our findings, shown with interaction analysis, is the supra-additive increase in SUDEP risk for individuals having at least one GTCS during the last year of observation and sleeping alone. This demonstrates again that unattended GTCS are the most important risk factor in SUDEP. ${ }^{24}$ More than two-thirds of all cases exposed to both GTCS and not sharing a bedroom would be prevented by removal of one of these risk factors. This suggests that a patient with epilepsy with GTCS should share a room with someone else whenever possible. This can be difficult to organize but hopefully there will be an improvement in different types of seizure monitoring devices that could alert family members or caretakers when a seizure is detected. No prospective studies regarding the effectiveness of seizure monitoring devices in preventing SUDEP have been conducted.

Other risk factors could be hidden and sleeping alone could be a marker for fewer social connections/networks. We found substance abuse to be a risk factor that can be connected to a reduced social network. This field needs further research.

Early case-control studies identified polytherapy with AEDs as a risk factor for SUDEP. ${ }^{2,4,6}$ However, with pooled data from 4 case-control studies, polytherapy was no longer a risk factor after adjustment for GTCS frequency. ${ }^{25}$ We did find excess risk in individuals with polytherapy; however, once we adjusted for GTCS, both monotherapy and polytherapy was associated with a reduced risk of SUDEP. These observations are in line with the meta-analysis of placebo-controlled randomized add-on trials in refractory epilepsy, which showed a substantially lower SUDEP risk among those randomized to adjunctive active treatment compared with placebo. ${ }^{26}$ A major limitation of this meta-analysis, however, was that adjustment for GTCS frequency was not possible. Our findings indicate that AEDs may have a protective effect beyond the seizurecontrolling properties. These potential mechanisms remain to be explored. 
Several studies have observed a reduced SUDEP risk after successful epilepsy surgery. ${ }^{27,28}$ We could not confirm these findings, but our analyses were hampered by small numbers. Treatment with VNS was associated with a reduced risk of SUDEP. A possible protective effect of VNS has been discussed before, ${ }^{29}$ but our data should be interpreted with caution given the small numbers.

Comorbid mental health disorders have previously been associated with excess risk of SUDEP, ${ }^{13}$ but we did not observe an association once GTCS frequency was taken into account. In line with the pooled analysis ${ }^{6}$ of previous case-control studies, substance abuse, including alcohol abuse, was associated with an increased risk for SUDEP. This should be considered when counseling individual patients. We detected no increased risk associated with a medical history of ischemic heart disease, heart failure, myocarditis, cardiomyopathy, or arrhythmias. Neither was there an increased risk in individuals with a history of other neurologic disorders or those with a history of chronic lower respiratory diseases. It is conceivable that patients with epilepsy with comorbid cardiovascular and respiratory diseases are more likely to be classified as possible SUDEP, which was not included in our analysis.

The strengths of this study are its size, the population-based nationwide nature, and the fact that the controls came from the same population as the cases, and furthermore, that we were able to attain records for $97 \%$ of the 1,275 potential controls. In addition, the validity of the epilepsy diagnosis was ascertained with chart review, and those not meeting the epilepsy criteria were excluded. Among the weaknesses are that patient records have their inherent limitations, which can have an effect on, e.g., the possibility to classify epilepsy syndromes, even though we had extensive records for most cases and controls. In addition, the authors extracting information were not blinded to the outcome, and were aware of previous reports on SUDEP risk factors, which may introduce bias. The information was collected identically using a standardized protocol for both cases and controls. It is possible that information on living conditions was better documented among cases due to the more extensive records in connection with their death. However, information on living conditions was missing in only a small fraction of the controls $(4.8 \%, \mathrm{n}=55)$, compared to in none of the SUDEP cases, and it is unlikely that this had a major effect on our results.

Having GTCS, nocturnal GTCS, and living alone are associated with markedly increased risk of SUDEP. Combining high frequency of GTCS and living alone is associated with a dramatically increased SUDEP risk, suggesting that unattended GTCS play a major role. The data suggest that better supervision is needed for high-risk patients with uncontrolled GTCS. However, such efforts to reduce SUDEP risks must be balanced against each patient's right to independence and integrity, which can only be done on an individual basis. Lately, there has been an increasing interest in the use of seizure detection devices, but it remains to be shown if these can reduce the SUDEP risk. ${ }^{30,31}$ The currently most important preventive method is to prescribe more effective treatments that reduce the occurrence of GTCS. Our data suggest that even a treatment that does not reduce the overall seizure frequency, but that prevents focal seizures from evolving to bilateral tonic-clonic seizures, may be beneficial. In a subsequent analysis, we intend to focus in more detail on the role of drug treatment utilizing data from the Swedish Drug Prescription Registry using the same study population.

\section{Study funding}

The study was supported by funding from Stockholm County Council, GlaxoSmithKline, and Citizens United for Research in Epilepsy. The sponsors had no influence on the conduct of the study, analysis, interpretation, writing of the manuscript, or the decision to publish the results.

\section{Disclosure}

O. Sveinsson has received grants from GSK, personal fees from Biogen, and honoraria to his institution from Biogen and UCB for lectures and advisory board, outside the submitted work. T. Andersson and S. Carlsson report no disclosures relevant to the manuscript. P. Mattsson received research support from the Uppsala County Council, Epilepsifonden, and Selander Foundation. T. Tomson is an employee of Karolinska Institutet, is associate editor of Epileptic Disorders, has received speaker's honoraria to his institution from Eisai, Sanofi, Sun Pharma, UCB, and Sandoz, and received research support from Stockholm County Council, EU, CURE, GSK, UCB, Eisai, and Bial. Go to Neurology.org/N for full disclosures.

\section{Publication history}

Received by Neurology May 4, 2019. Accepted in final form August 5, 2019.

\begin{tabular}{|c|c|c|c|}
\hline Name & Location & Role & Contribution \\
\hline $\begin{array}{l}\text { Olafur } \\
\text { Sveinsson, } \\
\text { MD, MSc }\end{array}$ & $\begin{array}{l}\text { Karolinska } \\
\text { Institutet }\end{array}$ & Author & $\begin{array}{l}\text { Major role in design of study and } \\
\text { acquisition of data, drafted the } \\
\text { manuscript for intellectual } \\
\text { content }\end{array}$ \\
\hline $\begin{array}{l}\text { Tomas } \\
\text { Andersson, } \\
\text { BSc }\end{array}$ & $\begin{array}{l}\text { Karolinska } \\
\text { Institutet }\end{array}$ & Author & $\begin{array}{l}\text { Statistical analysis, interpreted } \\
\text { the data, revised the manuscript } \\
\text { for intellectual content }\end{array}$ \\
\hline $\begin{array}{l}\text { Peter } \\
\text { Mattsson, } \\
\text { MD, PhD }\end{array}$ & $\begin{array}{l}\text { University } \\
\text { of Uppsala }\end{array}$ & Author & $\begin{array}{l}\text { Interpreted the data, revised the } \\
\text { manuscript for intellectual } \\
\text { content }\end{array}$ \\
\hline $\begin{array}{l}\text { Sofia } \\
\text { Carlsson, } \\
\text { PhD }\end{array}$ & $\begin{array}{l}\text { Karolinska } \\
\text { Institutet }\end{array}$ & Author & $\begin{array}{l}\text { Design of study, interpreted the } \\
\text { data, revised the manuscript for } \\
\text { intellectual content }\end{array}$ \\
\hline $\begin{array}{l}\text { Torbjörn } \\
\text { Tomson, } \\
\text { MD, PhD }\end{array}$ & $\begin{array}{l}\text { Karolinska } \\
\text { Institutet }\end{array}$ & Author & $\begin{array}{l}\text { Major role in design of study, } \\
\text { interpreted the data, revised the } \\
\text { manuscript for intellectual } \\
\text { content }\end{array}$ \\
\hline
\end{tabular}




\section{References}

1. Thurman DJ, Hesdorffer DC, French JA. Sudden unexpected death in epilepsy: assessing the public health burden. Epilepsia 2014;55:1479-1485.

2. Walczak TS, Leppik IE, D'Amelio M, et al. Incidence and risk factors in sudden unexpected death in epilepsy: a prospective cohort study. Neurology 2001;56: 519-525.

3. Hitiris N, Suratman S, Kelly K, Stephen LJ, Sills GJ, Brodie MJ. Sudden unexpected death in epilepsy: a search for risk factors. Epilepsy Behav 2007;10:138-141.

4. Nilsson L, Farahmand BY, Persson PG, Thiblin I, Tomson T. Risk factors for sudden unexpected death in epilepsy: a case-control study. Lancet 1999;353:888-893.

5. Langan Y, Nashef L, Sander JW. Case-control study of SUDEP. Neurology 2005;64: 1131-1133.

6. Hesdorffer DC, Tomson T, Benn E, et al. Combined analysis of risk factors for SUDEP. Epilepsia 2011;52:1150-1159.

7. Harden C, Tomson T, Gloss D, et al. Practice guideline summary: sudden unexpected death in epilepsy incidence rates and risk factors: report of the guideline development, dissemination, and implementation Subcommittee of the American Academy of Neurology and the American Epilepsy Society. Neurology 2017;88: 1674-1680.

8. Tomson T, Surges R, Delamont R, Haywood S, Hesdorffer DC. Who to target in sudden unexpected death in epilepsy prevention and how? Risk factors, biomarkers, and intervention study designs. Epilepsia 2016;57( suppl 1):4-16.

9. Nashef L. Sudden unexpected death in epilepsy: terminology and definitions. Epilepsia 1997;38(suppl 11):6-8.

10. Annegers IF. United States perspective on definitions and classifications. Epilepsia 1997;38(suppl 11):9-12.

11. Ludvigsson JF, Andersson E, Ekbom A, et al. External review and validation of the Swedish National Inpatient Register. BMC Public Health 2011;11:450.

12. Johansson LA, Björkenstam C, Westerling R. Unexplained differences between hospital and mortality data indicated mistakes in death certification: an investigation of 1,094 deaths in Sweden during 1995. J Clin Epidemiol 2009;62: 1202-1209.

13. Sveinsson O, Andersson T, Carlsson S, Tomson T. The incidence of SUDEP: a nationwide population-based cohort study. Neurology 2017;89:170-177.

14. Fisher RS, Cross JH, French JA, et al. Operational classification of seizure types by the International League Against Epilepsy: position paper of the ILAE Commission for Classification and Terminology. Epilepsia 2017;58:522-530.

15. Scheffer IE, Berkovic S, Capovilla G, et al. ILAE classification of the epilepsies: position paper of the ILAE Commission for Classification and Terminology. Epilepsia 2017;58:512-521.
16. Ludvigsson JF, Svedberg P, Olén O, Bruze G, Neovius M. The longitudinal integrated database for health insurance and labour market studies (LISA) and its use in medical research. Eur J Epidemiol 2019;34:423-437.

17. Vandenbroucke JP, Pearce N. Case-control studies: basic concepts. Int J Epidemiol 2012;41:1480-1489.

18. Andersson T, Alfredsson L, Kallberg H, Zdravkovic S, Ahlbom A. Calculating measures of biological interaction. Eur J Epidemiol 2005;20:575-579.

19. Sveinsson O, Andersson T, Carlsson S, Tomson T. Circumstances of SUDEP: a nationwide population-based case-series. Epilepsia 2018;59:1074-1082.

20. Lhatoo SD, Nei M, Raghavan M, et al. Nonseizure SUDEP: sudden unexpected death in epilepsy without preceding epileptic seizures. Epilepsia 2016;57:1161-1168.

21. Ryvlin P, Nashef L, Lhatoo SD, et al. Incidence and mechanisms of cardiorespiratory arrests in epilepsy monitoring units (MORTEMUS): a retrospective study. Lancet Neurol 2013;12:966-977.

22. Lamberts RJ, Thijs RD, Laffan A, Langan Y, Sander JW. Sudden unexpected death in epilepsy: people with nocturnal seizures may be at highest risk. Epilepsia 2012;53: 253-257.

23. van der Lende M, Hesdorffer DC, Sander JW, Thijs RD. Nocturnal supervision and SUDEP risk at different epilepsy care settings. Neurology 2018;91:e1508-e1518.

24. Devinsky O, Hesdorffer DC, Thurman DJ, Lhatoo S, Richerson G. Sudden un expected death in epilepsy: epidemiology, mechanisms, and prevention. Lancet Neurol 2016;15:1075-1078.

25. Hesdorffer DC, Tomson T, Benn E, et al; ILAE Commission on Epidemiology (Subcommission on Mortality). Do antiepileptic drugs or generalized tonic-clonic seizure frequency increase SUDEP risk? A combined analysis. Epilepsia 2012;53: 249-252.

26. Ryvlin P, Cucherat M, Rheims S. Risk of sudden unexpected death in epilepsy in patients given adjunctive antiepileptic treatment for refractory seizures: a metaanalysis of placebo-controlled randomised trials. Lancet Neurol 2011;10:961-968.

27. Hennessy MJ, Langan $\mathrm{Y}$, Elwes RD, et al. A study of mortality after temporal lobe epilepsy surgery. Neurology 1999;53:1276-1283.

28. Sperling MR, Barshow S, Nei M, Asadi-Pooya AA. A reappraisal of mortality after epilepsy surgery. Neurology 2016;86:1938-1944.

29. Ryvlin P, So EL, Gordon CM, et al. Long-term surveillance of SUDEP in drug resistant epilepsy patients treated with VNS therapy. Epilepsia 2018;59:562-572.

30. Ryvlin P, Ciumas C, Wisniewski I, Beniczky S. Wearable devices for sudden unexpected death in epilepsy prevention. Epilepsia 2018;59(suppl 1):61-66.

31. Rugg-Gunn F, Duncan J, Hjalgrim H, Seyal M, Bateman L. From unwitnessed fatality to witnessed rescue: nonpharmacologic interventions in sudden unexpected death in epilepsy. Epilepsia 2016;57(suppl 1):26-34. 


\section{Neurology}

Clinical risk factors in SUDEP: A nationwide population-based case-control study

Olafur Sveinsson, Tomas Andersson, Peter Mattsson, et al.

Neurology 2020;94;e419-e429 Published Online before print December 12, 2019

DOI 10.1212/WNL.0000000000008741

This information is current as of December 12, 2019

Neurology ${ }^{\circledR}$ is the official journal of the American Academy of Neurology. Published continuously since 1951, it is now a weekly with 48 issues per year. Copyright Copyright (C) 2019 The Author(s). Published by Wolters Kluwer Health, Inc. on behalf of the American Academy of Neurology.. All rights reserved. Print ISSN: 0028-3878. Online ISSN: 1526-632X.

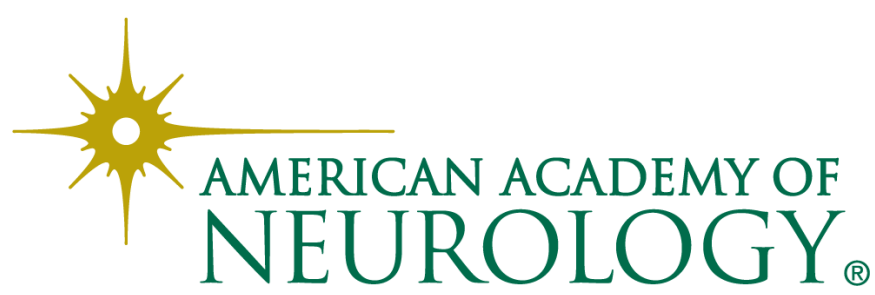




\section{Updated Information \& Services}

References

Citations

Subspecialty Collections

Errata

Permissions \& Licensing

Reprints including high resolution figures, can be found at: http://n.neurology.org/content/94/4/e419.full

This article cites 31 articles, 6 of which you can access for free at: http://n.neurology.org/content/94/4/e419.full\#ref-list-1

This article has been cited by 6 HighWire-hosted articles: http://n.neurology.org/content/94/4/e419.full\#\#otherarticles

This article, along with others on similar topics, appears in the following collection(s):

All Epilepsy/Seizures

http://n.neurology.org/cgi/collection/all_epilepsy_seizures Case control studies

http://n.neurology.org/cgi/collection/case_control_studies Clinical trials Observational study (Cohort, Case control)

http://n.neurology.org/cgi/collection/clinical_trials_observational_stud y_cohort_case_control

Generalized seizures

http://n.neurology.org/cgi/collection/generalized_seizures

An erratum has been published regarding this article. Please see next page or: /content/94/10/459.2.full.pdf

Information about reproducing this article in parts (figures,tables) or in its entirety can be found online at:

http://www.neurology.org/about/about_the_journal\#permissions

Information about ordering reprints can be found online:

http://n.neurology.org/subscribers/advertise

Neurology ${ }^{\circledR}$ is the official journal of the American Academy of Neurology. Published continuously since 1951, it is now a weekly with 48 issues per year. Copyright Copyright ( 2019 The Author(s). Published by Wolters Kluwer Health, Inc. on behalf of the American Academy of Neurology.. All rights reserved. Print ISSN: 0028-3878. Online ISSN: 1526-632X.

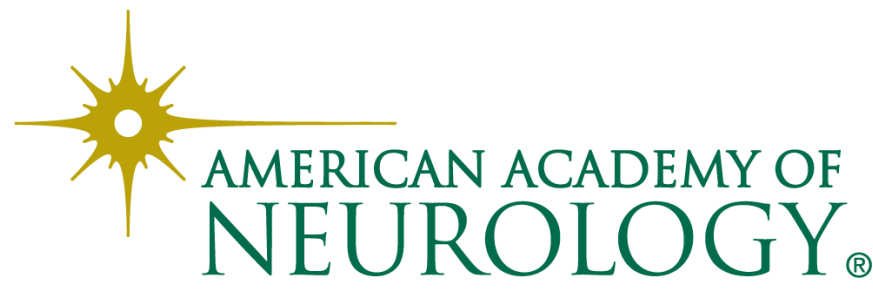




\title{
Disputes \& Debates: Editors' Choice
}

\author{
Steven Galetta, MD, FAAN, Section Editor
}

\section{Editors' note: Menarche, pregnancies, and breastfeeding do not modify long-term prognosis in multiple sclerosis}

In the article, "Menarche, pregnancies, and breastfeeding do not modify long-term prognosis in multiple sclerosis," Zuluaga et al. reported that age at menarche, pregnancy before or after the diagnosis of clinically isolated syndrome (CIS), and breastfeeding did not substantially modify the risk of progressing to clinically definite multiple sclerosis (CDMS) or disability accrual per the Expanded Disability Status Scale (EDSS) in a cohort of 501 female participants with CIS. In response, Drs. Jokubaitis and Dobson argued that the patients with CDMS should be examined separately for the EDSS outcomes because a substantial proportion of the overall cohort did not have a second clinical attack and did not meet either the McDonald 2010 or Barkhof criteria for MS. They seek additional details regarding the propensity score-matched score analysis because a smaller number of matched pairs could limit the generalizability of the results. In addition, they noted that the analyses for the association of pregnancy and breastfeeding on time to EDSS 3.0 were not adjusted for relapse and that the differences between exclusive breastfeeding and mixed feeding strategies merit further exploration in prospective studies. They also argue that the harmful effects of suspending disease-modifying treatments (DMTs) in those with aggressive disease who become pregnant should be considered. Responding to these comments, Drs. Tintoré et al. noted that they built the model for time to EDSS 3.0 over the CDMS subcohort, in addition to providing further details of the propensity score-matched analyses. They reported additional analyses for the adjusted hazard ratio for pregnancy (but not for breastfeeding) on considering the annualized relapse rate over the first 3 and 5 years of disease and acknowledged that additional details of breastfeeding were unavailable. Regarding the problem of suspending DMTs in pregnant patients, they noted that they are analyzing a subgroup of women treated with natalizumab or fingolimod. As greater numbers of young women become eligible for DMTs with more inclusive revisions of the McDonald criteria, neurologists are likely to encounter challenging questions about the association of pregnancies and breastfeeding with MS disease activity, and the attendant DMT-related dilemmas, in their practice.

Aravind Ganesh, MD, DPhil, and Steven Galetta, MD

Neurology ${ }^{\circledR} 2020 ; 94: 455$. doi:10.1212/WNL.0000000000009064

\section{Reader response: Menarche, pregnancies, and breastfeeding do not modify long-term prognosis in multiple sclerosis}

Vilija G. Jokubaitis (Melbourne) and Ruth Dobson (London) Neurology ${ }^{\circledR}$ 2020;94:455-456. doi:10.1212/WNL.0000000000009063

We read with interest the article by Zuluaga et al., ${ }^{1}$ which used the uniquely valuable Barcelona CIS (clinically isolated syndrome) cohort. ${ }^{2}$ However, evolving multiple sclerosis (MS) diagnostic and treatment landscapes must be taken into account when using this cohort to inform current practice.

Of those included in the analysis, ${ }^{1} 47 \%$ did not have a second clinical attack, $39 \%$ did not meet the McDonald 2010 criteria, and 32\% did not meet the Barkhof criteria for the diagnosis of MS. This 
raises questions about cohort baseline heterogeneity because 2 of the primary outcome measures are confirmed Expanded Disability Status Scale (EDSS) 3.0 or 6.0. There is an argument in favor of examining the clinically definite multiple sclerosis (CDMS) cohort separately to the nonCDMS cohort.

Regarding the propensity score-matched analyses, we are interested to know the matching strategy used, how many matched pairs were included in this analysis, the matching ratio, the median follow-up duration, and censoring strategy. Only 142 respondents had pregnancies after a $\mathrm{CIS}^{1}$; it is thus possible that fewer than 142 matched pairs were included, limiting the generalizability of these results.

It appears that the analyses of the impact of pregnancy and breastfeeding on time to EDSS 3.0 were not adjusted for relapse. Relapse, particularly early in the disease phase, and relapse recovery are among the strongest predictors of future disability accumulation.,

Breastfeeding was studied as both a dichotomous variable (breastfeeding vs not) and a timedependent event. ${ }^{1}$ However, exclusive breastfeeding may be protective in a way that mixed feeding is not. ${ }^{5} \mathrm{~A}$ truly prospective design is required to address the subtleties of this question.

The authors concluded that MS prognosis is not significantly affected by pregnancy once all other variables are considered. ${ }^{1}$ However, in the current era of highly active disease-modifying treatment (DMT) use, pregnancy does not occur in isolation. The potentially harmful effects of suspending DMT in those with aggressive disease must be taken into account when discussing family planning in MS. We look forward to future studies to help answer the questions that this study raises, which is of prime importance to women with MS.

1. Zuluaga MI, Otero-Romero S, Rovira A, et al. Menarche, pregnancies, and breastfeeding do not modify long-term prognosis in multiple sclerosis. Neurology 2019;92:e1507-e1516.

2. Tintore M, Rovira À, Río J, et al. Defining high, medium and low impact prognostic factors for developing multiple sclerosis. Brain 2015; 138:1863-1874.

3. Bermel RA, You X, Foulds P, et al. Predictors of long-term outcome in multiple sclerosis patients treated with interferon $\beta$. Ann Neurol 2013;73:95-103.

4. Jokubaitis VG, Spelman T, Kalincik T, et al. Predictors of long-term disability accrual in relapse-onset multiple sclerosis. Ann Neurol 2016;80:89-100.

5. Hellwig K, Rockhoff M, Herbstritt S, et al. Exclusive breastfeeding and the effect on postpartum multiple sclerosis relapses. JAMA Neurol 2015;72:1132-1138.

Copyright @ 2020 American Academy of Neurology

\section{Author response: Menarche, pregnancies, and breastfeeding do not modify long-term prognosis in multiple sclerosis}

Mar Tintoré (Barcelona, Spain), Santiago Perez-Hoyos (Barcelona, Spain), and Susana Otero-Romero

(Barcelona, Spain)

Neurology ${ }^{\circledR}$ 2020;94:456-457. doi:10.1212/WNL.0000000000009065

We thank Drs. Jokubaitis and Dobson for the comment on our article. ${ }^{1}$

We built the model for the time to Expanded Disability Status Scale (EDSS) 3.0 over the clinically definite multiple sclerosis (CDMS) subcohort. The adjusted hazard ratio (aHR [CI $95 \%]$ ) associated to pregnancy is $\mathrm{aHR}=1.26$, CI $95 \%(0.62,2.59)$.

Regarding the propensity score-matched analyses, we decided to perform inverse probability (IP) weighting to create the new pseudocohort to minimize the association between covariates and pregnancy status. Thus, no matching was performed, but we assigned IP weights to each of the patients in the cohort. The probability of being pregnant at any time, given the set of 
covariates, was estimated via a logistic regression adjusted for age at clinically isolated syndrome (CIS), topography of the CIS, oligoclonal bands (OB), number of T2 baseline lesions, treatment status (as time dependent), number of T2 lesions at first year, and CDMS (as time dependent).

We totally agree with the issue noted about not adjusting for relapse in the analyses of impact of pregnancy and breastfeeding on time to EDSS 3.0. Incorporating relapses in the adjusted model is key to predict disability. The adjusted hazard ratio for pregnancy, considering the annualized relapse rate over the first 3 years of disease, is aHR $=1.15$, CI $95 \%(0.56,2.36)$. When computing the annualized relapse rate within the first 5 years of disease, we obtain an aHR = 1.45 , CI $95 \%(0.70,3.02)$. A further step that we are exploring for this analysis is to include relapses as a time-varying event with the aim of approaching in a more realistic way the dynamic nature of the disease. We also agree that future research must focus on more precise modalities of breastfeeding, such as mixed or exclusive breastfeeding. Unfortunately, this information was missing in our study. ${ }^{1}$

In the era of high-efficacy drugs, suspending disease-modifying treatments may be harmful for patients with aggressive multiple sclerosis. To answer the questions our study raised, we are in the process of independently analyzing a subgroup of pregnant women treated with natalizumab or fingolimod.

1. Zuluaga MI, Otero-Romero S, Rovira A, et al. Menarche, pregnancies, and breastfeeding do not modify long-term prognosis in multiple sclerosis. Neurology 2019;92:e1507-e1516.

Copyright (c) 2020 American Academy of Neurology

\section{Editors' note: Teaching Neurolmages: A rare case of Jacobsen syndrome with global diffuse hypomyelination of brain}

In the article "Teaching NeuroImages: A rare case of Jacobsen syndrome with global diffuse hypomyelination of brain," Patel et al. presented MRI fluid-attenuated inversion recovery (FLAIR) images at 18 months and 3 years of age in a boy with Jacobsen syndrome due to an 11q23-11q24 deletion. The images showed improvement in white matter abnormalities, which were termed hypomyelination by the authors. In response, Wolf et al. argued that hypomyelination is a permanent myelin deficit and is associated with a less hyperintense T2 white matter signal than is seen in this patient. They noted that the patient's deletion encompasses HEPACAM, a gene for which haploinsufficiency is associated with leukodystrophy that improves with time. They noted that the case is representative of limitations in extant classifications of leukodystrophies as either hypomyelinating or demyelinating. Responding to these comments, Patel et al. agreed that HEPACAM loss of function may account for some of the imaging abnormalities in Jacobsen syndrome but noted that macrocephaly and cysts (classical findings with HEPACAM mutations) are not typically seen in this syndrome. They noted that the original neuroradiologist interpretation termed the findings as global diffuse hypomyelination. This exchange highlights current uncertainties in the terminology surrounding the white matter abnormalities, particularly in the pediatric population.

Aravind Ganesh, MD, DPhil, and Steven Galetta, MD Neurology ${ }^{\circledR} 2020 ; 94: 457$. doi:10.1212/WNL.0000000000009066 


\section{Reader response: Teaching NeuroImages: A rare case of Jacobsen syndrome with global diffuse hypomyelination of brain}

Nicole I. Wolf (Amsterdam) and Marjo S. van der Knaap (Amsterdam)

Neurology ${ }^{\circledR}$ 2020;94:458. doi:10.1212/WNL.0000000000009070

With interest we read the report by Patel et al. ${ }^{1}$ concerning a patient with Jacobsen syndrome due to an 11q23-11q24 deletion and MRI evidence for leukodystrophy with improvement at a follow-up, substantiated by FLAIR images. The authors claimed that these abnormalities represent hypomyelination. Hypomyelination is defined as a significant and permanent myelin deficit. $^{2}$ Its MRI appearance is characterized by a diffusely hyperintense T2 white matter (WM) signal, which is less high than the signal in other leukodystrophies ${ }^{2,3}$ and certainly less high than the WM signal in the patient discussed here, ${ }^{1}$ who has strongly T2-hyperintense WM signal abnormalities.

The chromosomal deletion encompasses HEPACAM. Heterozygous and biallelic mutations in this gene cause megalencephalic leukodystrophy with subcortical cysts (MLC), a vacuolating leukodystrophy with macrocephaly. In dominant HEPACAM mutations, the leukodystrophy improves over time. ${ }^{4}$ In Jacobsen syndrome, HEPACAM haploinsufficiency was earlier assumed to cause leukodystrophy. ${ }^{5}$

Why did the authors classify their case as hypomyelination? Many neurologists still categorize leukodystrophies in hypomyelinating and demyelinating disorders. ${ }^{3}$ Perhaps the MRI improvement, not compatible with a demyelinating (progressive) disorder, prompted them to label this leukodystrophy hypomyelination? This case nicely illustrated that not all leukodystrophies are progressive and that there are more leukodystrophy categories beyond hypomyelination and demyelination. ${ }^{3}$

1. Patel H, Kumar A, Raymond G, Mainali G. Teaching NeuroImages: a rare case of Jacobsen syndrome with global diffuse hypomyelination of brain. Neurology 2019;92:e1665-e1666.

2. Pouwels PJ, Vanderver A, Bernard G, et al. Hypomyelinating leukodystrophies: translational research progress and prospects. Ann Neurol 2014;76:5-19.

3. van der Knaap MS, Schiffmann R, Mochel F, Wolf NI. Diagnosis, prognosis and treatment of the leukodystrophies. Lancet Neurol 2019; 18:962-972.

4. van der Knaap MS, Boor I, Estévez R. Megalencephalic leukoencephalopathy with subcortical cysts: chronic white matter oedema due to a defect in brain ion and water homoeostasis. Lancet Neurol 2012;11:973-985.

5. Yamamoto T, Shimada S, Shimojima K, et al. Leukoencephalopathy associated with 11q24 deletion involving the gene encoding hepatic and glial cell adhesion molecule in two patients. Eur J Med Genet 2015;58:492-496.

Copyright (c) 2020 American Academy of Neurology

\section{Author response: Teaching NeuroImages: A rare case of Jacobsen syndrome with global diffuse hypomyelination of brain}

Himadri Patel (Hershey, PA), Ashutosh Kumar (Hershey, PA), Gerald Raymond (Hershey, PA),

and Gayatra Mainali (Hershey, PA)

Neurology ${ }^{\circledR} 2020 ; 94: 458-459$. doi:10.1212/WNL.0000000000009069

We thank Drs. Wolfe and Van der Knaap for their insightful comment, on our Teaching NeuroImages study, ${ }^{1}$ and clarification of their precise definition of hypomyelinating disorders. We agree that HEPACAM loss of function may account for some of the issue in imaging in Jacobsen syndrome, but it does not appear to be the entire explanation, given the lack of macrocephaly or cysts in most patients reported. Regarding the hypomyelination classification, this was derived from the original radiology report, interpreted 
by the neuroradiologist, as a global diffuse hypomyelination with mild diffuse brain atrophy. Further longitudinal studies would certainly be of interest.

1. Patel H, Kumar A, Raymond G, Mainali G. Teaching NeuroImages: a rare case of Jacobsen syndrome with global diffuse hypomyelination of brain. Neurology 2019;92:e1665-e1666.

Copyright (c) 2020 American Academy of Neurology

CORRECTIONS

\section{Clinical and neural responses to cognitive behavioral therapy for functional tremor \\ Neurology ${ }^{\circledR}$ 2020;94:459. doi:10.1212/WNL.0000000000008714}

In the article "Clinical and neural responses to cognitive behavioral therapy for functional tremor" by Espay et al., ${ }^{1}$ the full author's name should have appeared throughout as W. Curt LaFrance, Jr. The authors regret the error.

\section{Reference}

1. Espay AJ, Ries S, Maloney T, et al. Clinical and neural responses to cognitive behavioral therapy for functional tremor. Neurology 2019; 93:e1787-e1798.

\section{Clinical risk factors in SUDEP}

A nationwide population-based case-control study

Neurology ${ }^{\circledR}$ 2020;94:459. doi:10.1212/WNL.0000000000009154

In the article "Clinical risk factors in SUDEP: A nationwide population-based case-control study" by Sveinsson et al., the bottom box in figure 1 should read " $n=255$ " and the fifth box down on the right should read "Controls." The editorial staff regret the errors.

\section{Reference}

1. Sveinsson O, Andersson T, Mattsson P, Carlsson S, Tomson T. Clinical risk factors in SUDEP: a nationwide population-based casecontrol study. Neurology 2020;94:e419-e429.

\section{Genetic determinants of disease severity in the myotonic dystrophy type 1 OPTIMISTIC cohort}

Neurology ${ }^{\circledR}$ 2020;94:459. doi:10.1212/WNL.0000000000008715

In the article "Genetic determinants of disease severity in the myotonic dystrophy type 1 OPTIMISTIC cohort" by Cumming et al., ${ }^{1}$ the study funding section should have read "Study funded by European Union's Seventh Framework Programme (FP7/2007-2013) under grant agreement number 305697 (the OPTIMISTIC project), the Wellcome Centre for Mitochondrial Research (ref 203105/Z/16/Z)), and donations to the DGM group from the Myotonic Dystrophy Support Group. The funders had no role in the study design, data collection, analysis, interpretation of data, writing the report, or decisions regarding when to submit publications." The authors regret the error.

\section{Reference}

1. Cumming SA, Jimenez-Moreno C, Okkersen K, et al. Genetic determinants of disease severity in the myotonic dystrophy type 1 OPTIMISTIC cohort. Neurology 2019;93:e995-e1009. 